\title{
Quantitation of $\mathrm{N}$-Acetyl-S-(9,10-dihydro-9-hydroxy-10- phenanthryl)-L-cysteine in Human Urine: Comparison with Glutathione-S-transferase Genotypes in Smokers
}

\author{
Pramod Upadhyaya, Priyanka Rao, J. Bradley Hochalter, Zhong-ze Li, Peter W. Villalta, and \\ Stephen S. Hecht \\ The Cancer Center, University of Minnesota, Minneapolis, MN 55455
}

\begin{abstract}
There are major inter-individual differences in carcinogenic polycyclic aromatic hydrocarbon (PAH) metabolism in humans, and it has been hypothesized that these differences may be related to cancer risk in smokers and other exposed people. One important pathway of PAH metabolism involves detoxification of epoxide and diol epoxide metabolites by reaction with glutathione, catalyzed by glutathione- $S$-transferases (GSTs). Interindividual differences in these pathways have been examined by genotyping methods, investigating polymorphisms in GSTM1 and GSTP1. We are developing a phenotyping approach to assessing individual differences in PAH metabolism by quantifying human urinary metabolites of the ubiquitous PAH phenanthrene (1). In this study, we developed a method for quantitation of a mercapturic acid, $N$-acetyl-S-(9,10-dihydro-9-hydroxy-10-phenanthryl)-Lcysteine (PheO-NAC, 12), the end product of reaction of phenanthrene-9,10-epoxide (11) with glutathione. $\left[\mathrm{D}_{10}\right] \mathrm{PheO}-\mathrm{NAC}$ was added to the urine as internal standard, and the PheO-NAC fraction was enriched by solid phase extraction. PheO-NAC was quantified by liquid chromatographyelectrospray ionization-tandem mass spectrometry with selected reaction monitoring. The detection limit was approximately $4 \mathrm{fmol} / \mathrm{mL}$ urine. PheO-NAC was detected in the urine of 46 of 104 smokers, mean $( \pm$ S.D.) $57.9 \pm 144 \mathrm{fmol} / \mathrm{mL}$. PheO-NAC was detected significantly more frequently ( $\mathrm{P}<0.0001)$ in subjects who were GSTM1 positive than in those who were GSTM1 null, and the levels of PheO-NAC were significantly higher in the GSTM1 positive subjects, consistent with a role for GSTM1 in the detoxification of phenanthrene-9,10-epoxide. There were no significant relationships between PheO-NAC levels and the occurrence of two GSTP1 polymorphisms. The results of this study provide the first evidence for a PAH-derived mercapturic acid in human urine and should be useful in the development of a phenotyping approach to assess individual differences in PAH metabolism.
\end{abstract}

\section{Introduction}

Polycyclic aromatic hydrocarbons (PAH) are considered to be among the most important carcinogens in cigarette smoke (1-3). Multiple PAH occur in smoke, and some of these are potent locally acting carcinogens, readily inducing tumors when applied to mouse skin or directly in the rodent respiratory tract (1). Fractions of cigarette smoke condensate enriched in PAH have tumor initiating activity (4). There is a similarity between the types of mutations observed in the $p 53$ gene in lung tumors from smokers and those seen in reactions of PAH diol epoxides with the $p 53$ gene in vitro, or in cells treated with benzo $[a]$ pyrene $(\mathrm{BaP})$, a prototypic

*To whom correspondence should be addressed: The Cancer Center, University of Minnesota, MMC 806, 420 Delaware St SE, Minneapolis, MN 55455, USA. ph: (612) 626-7604 fax: (612) 626-5135 e-mail: hecht002@umn.edu. 
PAH carcinogen $(5,6)$. BaP has recently been classified as carcinogenic to humans by the International Agency for Research on Cancer (7).

PAH require metabolic activation to exert their carcinogenic effects, and there are competing detoxification pathways (8). Many studies have shown that there are large interindividual differences in human PAH metabolism, leading to the hypothesis that exposed individuals such as smokers who metabolically activate PAH effectively are at higher risk for cancer than those who detoxify these compounds effectively (9-16). This hypothesis has been tested in multiple investigations in the literature in which polymorphisms in PAH metabolizing genes, particularly CYP and GST genes, have been investigated with respect to cancer incidence in smokers (17-24). The results of these studies provide some support for the hypothesis that CYP1A1 polymorphisms, particularly in combination with GSTM1 null, may increase the risk for lung cancer in smokers.

PAH metabolism is extremely complex, with many different enzymes being involved (8). We believe that inter-individual differences in PAH metabolism are too complicated to be estimated by genotyping, and have therefore been developing a carcinogen metabolite phenotyping approach, in which PAH metabolites would be quantified in human urine. The advantage of this approach is that it integrates all genetic and environmental effects on PAH metabolism. We have focused on phenanthrene (Phe) metabolites in this research. Phe is the simplest PAH with a bay region, a feature closely associated with carcinogenicity, although Phe is not considered to be carcinogenic $(25,26)$. We chose Phe because it is prevalent in the human environment and its metabolites are readily detected in urine, as opposed for example to those of $\mathrm{BaP}(27)$. In previous studies, we have described methods to quantify $r-1, t-2,3, c-4-$ tetrahydroxy- 1,2,3,4-tetrahydrophenanthrene (PheT, 5), the end product of the diol epoxide metabolic activation pathway common to many PAH, and phenanthrols (HOPhe, 6-10) in human urine (Scheme 1) (28-31). In this study, we have focused on the detoxification of Phe by the glutathione- $S$-transferase (GST) pathway. Earlier reports demonstrated that a major mercapturic acid found in the urine of rats, rabbits, and guinea pigs dosed with Phe was $\mathrm{N}$ acetyl-S-(9,10- dihydro-9-hydroxy-10-phenanthryl)-L-cysteine (PheO-NAC, 12,Scheme 1) $(32,33)$. Therefore, we have developed a method for quantitation of this metabolite in human urine. We are aware of no published studies on analysis of mercapturic acids of PAH in human urine.

\section{Materials and Methods}

\section{Apparatus and chromatography}

HPLC was carried out with a Waters system (Millipore, Waters Division, Milford, MA), equipped with a model 440 UV detector or a model 991 photodiode array detector. A $250 \times$ $10 \mathrm{~mm}$ Phenomenex Luna $5 \mu \mathrm{m}, \mathrm{C} 18$ column (Phenomenex, Torrance, $\mathrm{CA}$ ) was eluted with $65 \% 32 \mathrm{mM} \mathrm{NH}_{4} \mathrm{HCO}_{3}$ and $35 \% \mathrm{CH}_{3} \mathrm{OH}$ at a flow rate of $3 \mathrm{~mL} / \mathrm{min}$. This HPLC system was used for purification and identification of standard PheO-NAC and $\left[\mathrm{D}_{10}\right] \mathrm{PheO}-\mathrm{NAC}$.

Oasis MAX and MCX LP extraction cartridges $(6 \mathrm{cc}, 500 \mathrm{mg}$ ) were purchased from Waters. Strata-X polymeric sorbent $(33 \mu \mathrm{m}, 30 \mathrm{mg} / 1 \mathrm{~mL})$ was obtained from Phenomenex.

LC-ESI-MS/MS for characterization of PheO-NAC was carried out with a Thermo Finnigan LCQ Deca (Thermo Electron LC/MS Division, San Jose, CA) ion trap mass spectrometer interfaced with a Waters Alliance 2690 HPLC multi-solvent delivery system and equipped with an SPD-10 A UV detector (Shimadzu Scientific Instruments). A Prosphere $300 \mathrm{C} 18$ guard column $(7.5 \times 4.6 \mathrm{~mm}, 5 \mu \mathrm{m}$, Alltech Associates Inc., Deerfield, IL) was connected to a Prosphere $300 \mathrm{PAH}$ column $(250 \times 4.6 \mathrm{~mm}, 5 \mu \mathrm{m})$. The column was eluted with $32 \mathrm{mM}$ $\mathrm{NH}_{4} \mathrm{HCO}_{3}$ and $\mathrm{CH}_{3} \mathrm{OH}$. The gradient program started with $100 \% 32 \mathrm{mM} \mathrm{NH}_{4} \mathrm{HCO}_{3}$ and the 
proportion of $\mathrm{CH}_{3} \mathrm{OH}$ was increased by $10 \%$ every $10 \mathrm{~min}$ for $60 \mathrm{~min}$ at a flow rate of $0.7 \mathrm{~mL} /$ min. The ESI source was set in negative ion mode as follows: voltage, $5 \mathrm{kV}$; current, $80 \mu \mathrm{A}$; and capillary temperature, $275^{\circ} \mathrm{C}$. MS/MS data were acquired with the following parameters: isolation width, 1.5; activation amplitude, $30.0 \%$; activation $\mathrm{Q}, 0.25$; and activation time, 30 $\min$. The data were acquired and smoothed 7 times using the Gaussian algorithm provided with the ICIS data acquisition and processing software.

Quantitative LC-ESI-MS/MS for analysis of urine was performed using a Finnigan TSQ Quantum Discovery MAX or Ultra AM instrument (Thermo Electron, San Jose, CA) coupled to an Agilent 1100 Capillary HPLC system. The MS was operated in the negative ion ESI mode. An Agilent 1100 capillary flow HPLC (Agilent Technologies, Palo Alto, CA) equipped with a $250 \times 0.5 \mathrm{~mm} 5 \mu \mathrm{m} \mathrm{C} 18$ column (Agilent Zorbax SB-C18) and a Krudkatcher disposable pre- column filter (Phenomenex) was used. It was eluted with $0.1 \%$ aqueous $\mathrm{HCOOH}$ and $\mathrm{CH}_{3} \mathrm{CN}$, at $10 \mu \mathrm{L} / \mathrm{min}$. The gradient was as follows [\% $\mathrm{CH}_{3} \mathrm{CN}$, time (min)]: $10 \%, 0-34 \mathrm{~min}$; $28 \%, 34-45 \mathrm{~min} ; 100 \%, 45-65 \mathrm{~min}$. For confirmation of co-elution of PheO-NAC and [ $\left.\mathrm{D}_{10}\right]$ PheO-NAC in a second system, solvent A was $15 \mathrm{mM} \mathrm{NH}_{4} \mathrm{OAc}$ and solvent $\mathrm{B}$ was $\mathrm{CH}_{3} \mathrm{OH}$. The gradient was as follows [\% A, time(min)]: 90\%-35\%, $40 \mathrm{~min} ; 0 \%, 15 \mathrm{~min}$. The flow rate was $10 \mu \mathrm{L} / \mathrm{min}$. The ESI source was set in the negative ion mode as follows: voltage, $5 \mathrm{kV}$; current, $50 \mu \mathrm{A}$; and heated ion transfer tube, $330^{\circ} \mathrm{C}$. The metabolites were measured by MS/ MS using the selected reaction monitoring (SRM) mode. The collision energy for all of the transitions was $15 \mathrm{eV}$, and the Ar collision gas pressure was 1.0 mTorr. The MS settings of the ion source were optimized using a standard solution of PheO-NAC and $\left[\mathrm{D}_{10}\right] \mathrm{PheO}-\mathrm{NAC}$ to produce maximum signals at $\mathrm{m} / z, 356$ and $\mathrm{m} / z, 366$ respectively. For MS/MS, the settings were adjusted to obtain signal maxima at $m / z, 356 \rightarrow 209$ for PheO-NAC and $m / z, 366 \rightarrow 218$ for $\left[D_{10}\right]$ Phe-NAC.

NMR spectra were obtained with a Varian Inova (Varian, Inc., Palo Alto, CA) instrument operating at $600 \mathrm{MHz}$ and $25^{\circ} \mathrm{C}$.

\section{Chemicals}

$N$-Acetyl-S-(9,10-dihydro-9-hydroxy-10-phenanthryl)-L-cysteine (PheONAC, 12) was prepared by the reaction of Phe-9,10-epoxide (11) (34) with $N$-acetyl-L-cysteine (SigmaAldrich, St. Louis, MO), essentially as described previously (35). The product was purified by HPLC to give 2 diastereomers of 12. Spectral data for peak 1: UV, $\lambda_{\max } 209.8,271.0 ;{ }_{1} \mathrm{H}-\mathrm{NMR}$ $\left(\mathrm{DMSO}_{-} \mathrm{d}_{6}\right) \delta 7.86(\mathrm{t}, J=6.6 \mathrm{~Hz}, 2 \mathrm{H}, \mathrm{Phe}-\mathrm{H} 4$ and H5), 7.69 (br, $1 \mathrm{H}, \mathrm{NH}), 7.39-7.25(\mathrm{~m}, 6 \mathrm{H}$, Phe-H1-3 and H6-8), 5.40 (br, 1H, OH), 4.68 (s, 1H, Phe-H9), 4.20 (s, 1H, Phe-H10), 4.15 (m, $1 \mathrm{H}, \mathrm{CHNH}(\mathrm{COOH})), 2.92\left(\mathrm{dd}, J=4.2,13.2 \mathrm{~Hz}, 1 \mathrm{H}, \mathrm{SCH}_{2} \mathrm{a}\right), 2.71(\mathrm{dd}, J=7.2,13.2 \mathrm{~Hz}, 1 \mathrm{H}$, $\mathrm{SCH}_{2 \mathrm{~b}}$ ), 1.82 (s, $3 \mathrm{H}, \mathrm{CH}_{3}$ ); $\mathrm{MS}$ (negative ion) $\mathrm{m} / z$ (rel. intensity) $356[\mathrm{M}-\mathrm{H}]^{-}(100) ; 338[\mathrm{M}$ $\left.-\mathrm{H}_{2} \mathrm{O}\right]^{-}$(9); $227\left[\mathrm{M}-\mathrm{CH}_{2} \mathrm{CH}(\mathrm{COOH}) \mathrm{NHCOCH}_{3}\right]^{-}$(29); $209\left[\mathrm{M}-\mathrm{CH}_{2} \mathrm{CH}(\mathrm{COOH})\right.$ $\left.\mathrm{NHCOCH}_{3}-\mathrm{H}_{2} \mathrm{O}\right]^{-}$(41). Spectral data for peak 2 were virtually identical to those of peak 1.

$\left[\mathrm{D}_{10}\right] \mathrm{PheO}-\mathrm{NAC}$ was prepared the same way from $\left[\mathrm{D}_{10}\right]$ Phe-9,10-epoxide, which in turn was synthesized from $\left[\mathrm{D}_{10}\right]$ Phe (Cambridge Isotope Laboratories, Andover, MA) (34). MS (negative ion) $\mathrm{m} / z$ (rel. intensity) $366[\mathrm{M}-\mathrm{H}]^{-}(100) ; 237\left[\mathrm{M}-\mathrm{CH}_{2} \mathrm{CH}(\mathrm{COOH})\right.$ $\left.\mathrm{NHCOCH}_{3}\right]^{-}$(30); $218\left[\mathrm{M}-\mathrm{CH}_{2} \mathrm{CH}(\mathrm{COOH}) \mathrm{NHCOCH}_{3}-\mathrm{HDO}\right]^{-}$(31).

\section{Subjects}

The study was approved by the University of Minnesota Research Subjects' Protection Program Institutional Review Board Human Subjects Committee. Smokers were recruited through flyers posted on the University of Minnesota campus and near campus, and from advertisements in newspapers and on radio and television. Interested participants called the Tobacco Use Research Center and were told that the study would involve submission of urine 
and blood samples. All subjects signed a consent form. One hundred and four subjects gave first morning urine samples and $30 \mathrm{~mL}$ of blood (collected in tubes containing EDTA). Nonsmokers were similarly recruited. Samples were stored at $-20^{\circ} \mathrm{C}$ until analysis.

\section{Analysis of PheO-NAC in urine}

A $5 \mathrm{~mL}$ urine sample was placed in an $8 \mathrm{~mL}$ silanized vial (Chrom Tech Inc., MN) and $1 \mathrm{pmol} /$ $\mathrm{mL}\left[\mathrm{D}_{10}\right]$ PheO-NAC was added as internal standard. $\mathrm{HCOOH}(200 \mu \mathrm{L})$ was added to the urine. The sample was loaded onto an Oasis MCX cartridge that was previously equilibrated using $6 \mathrm{~mL} \mathrm{CH}_{3} \mathrm{OH}$ and $6 \mathrm{~mL} \mathrm{2 \%}$ aqueous $\mathrm{HCOOH}$. The cartridge was then washed with the following solutions (\% in $\mathrm{H}_{2} \mathrm{O}$ ): $5 \mathrm{~mL}$ of $2 \% \mathrm{HCOOH}, 5 \mathrm{~mL}$ of $10 \% \mathrm{CH}_{3} \mathrm{OH}-2 \% \mathrm{HCOOH}, 5$ $\mathrm{mL}$ of $20 \% \mathrm{CH}_{3} \mathrm{OH}-2 \% \mathrm{HCOOH}, 3 \mathrm{~mL}$ of $30 \% \mathrm{CH}_{3} \mathrm{OH}-2 \% \mathrm{HCOOH}$ and $2 \mathrm{~mL}$ of $30 \%$ $\mathrm{CH}_{3} \mathrm{OH}$. The cartridge was then eluted with $5 \mathrm{~mL}$ of $80 \%$ aqueous $\mathrm{CH}_{3} \mathrm{OH}$ to collect the analyte. One $\mathrm{mL}$ of $1 \%$ aqueous $\mathrm{NH}_{4} \mathrm{HCO}_{3}$ was added to the $80 \% \mathrm{CH}_{3} \mathrm{OH}$ eluate and this fraction was evaporated to dryness on a Speedvac using a silanized vial.

The sample was redissolved in $1 \mathrm{~mL} \mathrm{H}_{2} \mathrm{O}$ and loaded on an Oasis MAX cartridge that had been previously equilibrated with $6 \mathrm{~mL} \mathrm{CH}_{3} \mathrm{OH}$ and $6 \mathrm{~mL}$ of $0.2 \mathrm{~N} \mathrm{KOH}$. The cartridge was washed twice with $6 \mathrm{~mL}$ of $0.2 \mathrm{~N} \mathrm{KOH}$, twice with $6 \mathrm{~mL} 0.01 \mathrm{~N}$ methanolic KOH, twice with $6 \mathrm{~mL} 1 \mathrm{M}$ $\mathrm{NH}_{4} \mathrm{OAc}$, once with $6 \mathrm{mLCH}_{3} \mathrm{OH}$, and once with $6 \mathrm{~mL}$ acetone. The cartridge was then washed with $6 \mathrm{~mL}$ of $2 \% \mathrm{HCOOH}$ in acetone to elute PheO-NAC. One and a half $\mathrm{mL}$ of $15 \%$ $\mathrm{NH}_{4} \mathrm{HCO}_{3}$ was added to this fraction and it was evaporated to dryness on a Speedvac using a silanized vial.

For desalting, the sample was dissolved in $3 \mathrm{~mL} \mathrm{H}_{2} \mathrm{O}$ and loaded onto a Strata-X polymeric sorbent that was previously activated using $1 \mathrm{~mL} \mathrm{CH}_{3} \mathrm{OH}$ and $1 \mathrm{~mL} \mathrm{H}_{2} \mathrm{O}$. The cartridge was washed with $1 \mathrm{~mL} \mathrm{H}_{2} \mathrm{O}$ and $1 \mathrm{~mL}$ of $10 \% \mathrm{CH}_{3} \mathrm{OH}$. The analyte was eluted using $1 \mathrm{~mL}$ of $90 \%$ $\mathrm{CH}_{3} \mathrm{OH}$. This fraction was collected in a $2 \mathrm{~mL}$ silanized vial and concentrated to approximately $300 \mu \mathrm{L}$ on the Speedvac. The solution was then transferred to an insert vial and concentrated to dryness. The residue was dissolved in $40 \mu \mathrm{L} \mathrm{H}_{2} \mathrm{O}$, and $5 \mu \mathrm{L}$ was analyzed by LC-ESI-MS/ MS-SRM. A calibration curve was constructed using 50-5000 fmol PheO-NAC and $1000 \mathrm{fmol}$ $\left[\mathrm{D}_{10}\right]$ PheO-NAC.

\section{Genotyping}

This was performed using Masscode by Bioserve Biotechnologies, Laurel, MD., as described previously (28).

\section{Statistical analysis}

All statistical analyses were implemented using SAS statistical software, version 9.1. Sociodemographic characteristics were summarized by standard descriptive statistical methods. Statistical comparisons of overall arithmetic means among groups were made using the Kruskal-Wallis test with 5\% significance level. Pearson's chisquare test was applied to test associations between categorical variables.

\section{Results}

The method for analysis of PheO-NAC is summarized in Scheme 2. [ $\left.\mathrm{D}_{10}\right] \mathrm{PheO}-\mathrm{NAC}$ was added to the urine as internal standard. PheO-NAC was enriched from the urine by three consecutive solid phase extraction steps. The first used a mixed reverse-phase cation exchange (MCX) cartridge. The reverse-phase properties of this cartridge retained PheO-NAC. The second used a mixed reverse-phase anion exchange (MAX) cartridge. The anion exchange properties of this cartridge effected further purification of PheO-NAC. After elution of PheONAC from the MAX cartridge with $\mathrm{HCOOH}$, the mixture was neutralized with $\mathrm{NH}_{4} \mathrm{OAc}$ 
to prevent acid catalyzed dehydration during removal of solvents. A Strata-X cartridge was then used to remove the salts formed in this step. The appropriate fraction from the Strata-X cartridge was analyzed by LC-ESI-MS/MS-SRM for $m / z \quad 356 \rightarrow 209$ (PheO-NAC) and $\mathrm{m} / z$ $366 \rightarrow 218$ ([D $\left.{ }_{10}\right]$ PheO-NAC). A typical chromatogram from a smoker's urine positive for PheO-NAC is illustrated in Figure 1. A clean peak matching the retention time of standard PheO-NAC was observed. This peak eluted 0.4-0.5 min later than the internal standard, $\left[\mathrm{D}_{10}\right] \mathrm{PheO}-\mathrm{NAC}$. Further evidence for the identity of the analyte was obtained in a second HPLC system, which separated the two diastereomers of trans-PheO-NAC (36). The analyte diastereomers again matched the retention time of standard PheO-NAC, and eluted 0.4-0.5 min later than those of the internal standard (Figure 2). Similar chromatograms were obtained for all positive samples, including those from non-smokers. A chromatogram from a urine sample in which PheO-NAC was not detected is illustrated in Figure 3.

A calibration curve showing the relationship between ratios of PheO-NAC: $\left[\mathrm{D}_{10}\right] \mathrm{PheONAC}$ and LC-ESI-MS/MS response is illustrated in Figure 4. The precision of the analysis was determined by replicate analyses of 8 aliquots of a non-smoker's urine sample, giving a relative standard deviation of $5.1 \%$. The detection limit of PheO-NAC was approximately $4 \mathrm{fmol} / \mathrm{mL}$ urine. Recovery averaged $65 \%$.

Our main focus in this study was analysis of PheO-NAC in the urine of smokers and the relationship of these data to GST genotypes. Urine samples from 104 smokers were analyzed. The smokers had a mean age of $38.3 \pm 12.4$ (S.D.) years (range $18-69$ ). They were $36 \%$ male, $65 \%$ Caucasian, $32 \%$ African-American, and 3\% other, and they smoked an average of 20.3 \pm 9.2 cigarettes per day (range $5-60$ ).

Forty-six of the 104 smokers' urine samples were positive for PheO-NAC, having analyte levels above $4 \mathrm{fmol} / \mathrm{mL}$ (Table 1). Levels of PheO-NAC in the positive samples ranged from $7-880 \mathrm{fmol} / \mathrm{mL}$. The mean ( \pm S.D.) of all samples from smokers was $58 \pm 140 \mathrm{fmol} / \mathrm{mL}$ (using a value of zero for the samples with no detectable analyte). There was no relationship between urinary PheO-NAC levels and number of cigarettes smoked per day, examined in categories of 1-15, 16-25, and 26-60 cigarettes per day. Levels of PheO-NAC were compared to those of PheT (5) and total HOPhe (6-10) in the same samples, which were $5.79 \pm 8.00 \mathrm{pmol} / \mathrm{mL}$ and $4.14 \pm 3.00 \mathrm{pmol} / \mathrm{mL}$, respectively, approximately 100 times greater than PheO-NAC. Levels of PheO-NAC correlated weakly with those of PheT $(\mathrm{R}=0.21, \mathrm{P}=0.03)$ and total HOPhe $(\mathrm{R}=0.22, \mathrm{P}=0.03)$. Urine samples from 6 non-smokers were also analyzed; 5 were positive for PheO-NAC, with values ranging from $160-680 \mathrm{fmol} / \mathrm{mL}$.

The relationship between PheO-NAC in urine and GST genotypes was investigated in the smokers. GSTM1 genotype data were available for 102 subjects, of whom 44 were GSTM1 positive and 58 had the null genotype. PheO-NAC was detected significantly more frequently $(P<0.0001)$ in subjects who were GSTM1 positive (30 of 44 subjects, $68 \%)$ than in those who were GSTM1 null (15 of 58 subjects, 26\%). Levels of PheO-NAC were significantly higher in smokers who were GSTM1 positive $(110 \pm 210)$ than in those who were GSTM1 null (16 \pm 32 , $P<0.0001)$.

For the GSTP1 I105V polymorphism, there were 29 subjects with the normal genotype, 60 heterozygotes, 12 homozygotes, and 3 uncharacterized. For the GSTP1A114V polymorphism, there were 85 normals, 17 heterozygotes, no homozygotes, and 2 uncharacterized. There were no significant relationships between PheO-NAC levels and the occurrence of either of these polymorphisms, when comparing heterozygotes, homozygotes, and normals. 


\section{Discussion}

The results of this study provide convincing evidence for the presence of a PAH mercapturic acid, PheO-NAC (12, Scheme 1), in human urine. The identity of $\mathbf{1 2}$ is supported by the following observations. First, the solid phase extraction properties of the analyte were consistent with those of standard 12. Second, LC-ESI-MS/MS with SRM for $m / z 356 \rightarrow 209$, corresponding to the fragmentation pattern shown below, produced a clean peak in positive urine samples, and this peak had the same relative retention time as standard 12, determined by comparison to that of the internal standard, $\left[\mathrm{D}_{10}\right] \mathrm{PheO}-\mathrm{NAC}$ (Figure 1).

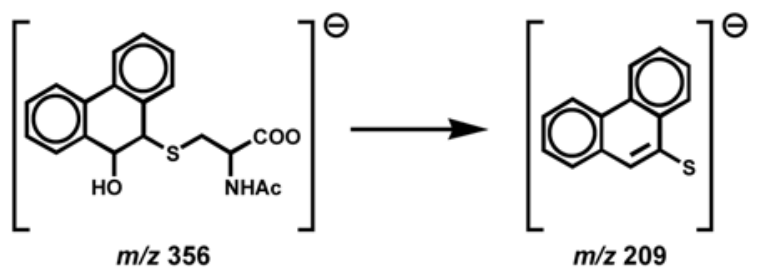

Third, chromatography in a second system, which separated the diastereomers of $\mathbf{1 2}$, again demonstrated that the analyte eluted at the proper retention time for standard PheO-NAC, as determined by comparison to the internal standard (Figure 2). The different ratios of isomer 1 and isomer 2 in the analyte vs. the internal standard (Figure 2) probably result from differing stereochemistry of addition in the enzymatic reaction vs. in the synthesis of $\left[\mathrm{D}_{10}\right] \mathrm{PheO}-\mathrm{NAC}$ from Phe-9,10-epoxide and $N$-acetyl-L-cysteine. Quantitation of this metabolite provides the first method for phenotyping human PAH metabolism by the mercapturic acid pathway.

Bay region and fjord region diol epoxides of $\mathrm{PAH}$, which are major ultimate carcinogens of compounds such as $\mathrm{BaP}$ and benzo[c]phenanthrene, are good substrates for human GSTA1, GSTP1, and GSTM1 enzymes, representing cytosolic GSTs of the alpha, pi, and mu classes, based on extensive in vitro studies (37-40). These studies demonstrate that, depending on stereochemistry and other factors, PAH diol epoxides should be detoxified by GSTs in humans. Similar studies do not appear to have been performed with anti-PheDE (4). Thus, GSTs can be expected to be protective against PAH carcinogenesis in smokers and other exposed individuals. While a phenotyping method for the mercapturic acids resulting from detoxification of anti- PheDE by GSTs would likely be a more direct way of assessing this detoxification pathway in humans, we have carried out our initial work on PheO-NAC because studies in laboratory animals indicated that this mercapturic acid might be more readily detected. We are presently investigating methods for analysis of mercapturic acids derived from anti-PheDE.

We found a highly significant relationship between detectability of PheO-NAC in the urine of smokers and GSTM1 genotype. Furthermore, the levels of PheO-NAC were significantly higher in the urine of GSTM1 positive individuals than in those with GSTM1 null. These results are completely consistent with in vitro studies, beginning with those of Warholm, et al. (41), which demonstrate that GSTM1-1 is a good catalyst of PAH epoxide detoxification, as well as for related compounds such as trans-stilbene oxide $(37-39,42)$. Nevertheless, it should be noted that PheO-NAC was detectable in $26 \%$ of the GSTM1 null individuals and was not detected in $32 \%$ of the individuals with GSTM1 present. The detection of PheO-NAC in GSTM1 null individuals is undoubtedly due to the presence of other GST enzymes, as well as possible non-enzymatic formation of this metabolite. Its lack of detection in GSTMI competent individuals could be influenced by the flux of metabolites through the Phe-9, 10-epoxide pathway. We observed no relationship between polymorphisms in the GSTPI gene and levels of PheO-NAC in urine. The GSTPII105V polymorphism codes for a protein with higher activity toward several PAH diol epoxides than the common form (43). Further processing of 
the initially formed GSH conjugates to mercapturic acids might also affect the amount of PheONAC in urine (44).

The lack of correlation between cigarettes per day and PheO-NAC levels was not surprising. First, there are significant environmental sources of Phe exposure other than cigarette smoke. In studies on PheT and HOPhe in human urine, we have detected these metabolites in every sample, be they from smokers or non-smokers (29-31). While PheT levels were higher in smokers than non-smokers, HOPhe levels were not $(29,30)$. Based on the limited number of non-smokers analyzed in this study, there do not appear to be major differences between levels of PheO-NAC in the urine of smokers and non-smokers. The effects of cigarette smoking on levels of Phe metabolites in urine are blunted by alternate sources of exposure to Phe as well as inter-individual differences in metabolism.

Carcinogen metabolite phenotyping may be an effective way to determine the relationship of $\mathrm{PAH}$ metabolism to cancer risk. With the development of the PheO-NAC assay described here, we now have three assays for urinary Phe metabolites - PheT, HOPhe, and PheONAC - that can be used in this approach. In ongoing studies, we have demonstrated that the PheT:HOPhe ratio is reasonably stable over time in most subjects, and that this ratio varies widely in smokers $(28,29)$. The PheT:HOPhe ratio is an activation:detoxification ratio, and PheO-NAC could be envisioned as another component of the denominator of this ratio.

In summary, the results of this study demonstrate, for the first time, the presence in human urine of a mercapturic acid derived from a PAH, Phe. This metabolite, PheO-NAC (12) was detected and quantified in the urine of 46 of 104 smokers. There was a significant correlation between detectability and levels of this mercapturic acid and GSTM1 genotype, demonstrating a solid phenotype-genotype relationship for this gene. There were no effects of GSTP1 polymorphisms on analyte levels. However, factors other than GST genotype apparently influence the presence of PheO-NAC, suggesting that phenotyping may be a better approach than genotyping for determining PAH detoxification via the GST pathway. We hope to incorporate this assay as part of a carcinogen metabolite phenotyping ratio to assess the relationship between PAH metabolism and cancer in exposed individuals.

\section{Acknowledgements}

This study was supported by grant CA-92025 from the National Cancer Institute. Stephen S. Hecht is an American Cancer Society Research Professor, supported by grant RP-00-138. Mass spectrometry was carried out in the Analytical Biochemistry Facility of the Cancer Center, supported in part by Cancer Center Support Grant CA-77598. We thank Dorothy Hatsukami and Joni Jensen of the University of Minnesota Transdisciplinary Tobacco Use Research Center, supported by grant DA-13333 from NIDA, for providing the urine samples.

\section{References}

1. International Agency for Research on Cancer. IARC Monographs on the Evaluation of Carcinogenic Risks to Humans. 83. IARC; Lyon, FR: 2004. Tobacco Smoke and Involuntary Smoking; p. 53-119.

2. Hecht SS. Tobacco carcinogens, their biomarkers, and tobacco-induced cancer. Nature Rev Cancer 2003;3:733-744. [PubMed: 14570033]

3. Hecht SS. Tobacco smoke carcinogens and lung cancer. J Natl Cancer Inst 1999;91:1194-1210. [PubMed: 10413421]

4. Hoffmann, D.; Schmeltz, I.; Hecht, SS.; Wynder, EL. Tobacco carcinogenesis. In: Gelboin, H.; Ts'o, POP., editors. Polycyclic Hydrocarbons and Cancer. Academic Press; New York: 1978. p. 85-117.

5. Pfeifer GP, Denissenko MF, Olivier M, Tretyakova N, Hecht SS, Hainaut P. Tobacco smoke carcinogens, DNA damage and p53 mutations in smokingassociated cancers. Oncogene 2002;21:7435-7451. [PubMed: 12379884] 
6. Liu Z, Muehlbauer KR, Schmeiser HH, Hergenhahn M, Belharazem D, Hollstein MC. p53 mutations in benzo(a)pyrene-exposed human p53 knock-in murine fibroblasts correlate with p53 mutations in human lung tumors. Cancer Res 2005;65:2583-2587. [PubMed: 15805253]

7. Straif K, Baan R, Grosse Y, Secretan B, El Ghissassi F, Cogliano V. Carcinogenicity of polycyclic aromatic hydrocarbons. Lancet Oncol 2005;6:931-932. [PubMed: 16353404]

8. Cooper CS, Grover PL, Sims P. The metabolism and activation of benzo[a]pyrene. Prog Drug Metab 1983;7:295-396.

9. Kellermann G, Shaw CR, Luyten-Kellerman M. Aryl hydrocarbon hydroxylase inducibility and bronchogenic carcinoma. N Engl J Med 1973;289:934-937. [PubMed: 4126515]

10. Harris CC, Autrup H, Connor R, Barrett LA, McDowell EM, Trump BF. Interindividual variation in binding of benzo[a]pyrene to DNA in cultured human bronchi. Science 1976;194:1067-1069. [PubMed: 982061]

11. Sabadie N, Richter-Reichhelm HB, Saracci R, Mohr U, Bartsch H. Interindividual differences in oxidative benzo $(a)$ pyrene metabolism by normal and tumorous surgical lung specimens from 105 lung cancer patients. Int J Cancer 1981;27:417-425. [PubMed: 6268552]

12. Nowak D, Schmidt-Preuss U, Jorres R, Liebke F, Rudiger HW. Formation of DNA adducts and watersoluble metabolites of benzo $[a]$ pyrene in human monocytes is genetically controlled. Int J Cancer 1988;41:169-173. [PubMed: 3338869]

13. McLemore TL, Adelberg S, Liu MC, McMahon NA, Yu SJ, Hubbard WC, Czerwinski M, Wood TG, Storeng R, Lubet RA, Eggleston JC, Boyd MR, Hines RN. Expression of CYP1A1 gene in patients with lung cancer: evidence for cigarette smoke-induced gene expression in normal lung tissue and for altered gene regulation in primary pulmonary carcinomas. J Natl Cancer Inst 1990;82:1333-1339. [PubMed: 2380990]

14. Kiyohara C, Nakanishi Y, Inutsuka S, Takayama K, Hara N, Motohiro A, Tanaka K, Kono S, Hirohata T. The relationship between CYP1A1 aryl hydrocarbon hydroxylase activity and lung cancer in a Japanese population. Pharmacogenetics 1998;8:315-323. [PubMed: 9731718]

15. Nebert DW. Drug-metabolizing enzymes, polymorphisms and interindividual response to environmental toxicants. Clin Chem Lab Med 2000;38:857-861. [PubMed: 11097340]

16. Alexandrov K, Cascorbi I, Rojas M, Bouvier G, Kriek E, Bartsch H. CYP1A1 and GSTM1 genotypes affect benzo[a]pyrene DNA adducts in smokers' lung: comparison with aromatic/hydrophobic adduct formation. Carcinogenesis 2002;23:1969-1977. [PubMed: 12507920]

17. Bartsch H, Nair U, Risch A, Rojas M, Wikman H, Alexandrov K. Genetic polymorphism of CYP genes, alone or in combination, as a risk modifier of tobacco-related cancers. Cancer Epidemiol Biomarkers \& Prev 2000;9:3-28.

18. Smith GB, Harper PA, Wong JM, Lam MS, Reid KR, Petsikas D, Massey TE. Human lung microsomal cytochrome P4501A1 (CYP1A1) activities: impact of smoking status and CYP1A1, aryl hydrocarbon receptor, and glutathione S- transferase M1 genetic polymorphisms. Cancer Epidemiol Biomarkers \& Prev 2001;10:839-853.

19. Le Marchand L, Guo C, Benhamou S, Bouchardy C, Cascorbi I, Clapper ML, Garte S, Haugen A, Ingelman-Sundberg M, Kihara M, Rannug A, Ryberg D, Stucker I, Sugimura H, Taioli E. Pooled analysis of the CYP1A1 exon 7 polymorphism and lung cancer (United States). Cancer Causes Control 2003;14:339-346. [PubMed: 12846365]

20. Benhamou S, Lee WJ, Alexandrie AK, Boffetta P, Bouchardy C, Butkiewicz D, Brockmoller J, Clapper ML, Daly A, Dolzan V, Ford J, Gaspari L, Haugen A, Hirvonen A, Husgafvel-Pursiainen K, Ingelman-Sundberg M, Kalina I, Kihara M, Kremers P, Le Marchand L, London SJ, Nazar-Stewart V, Onon-Kihara M, Rannug A, Romkes M, Ryberg D, Seidegard J, Shields P, Strange RC, Stucker I, To-Figueras J, Brennan P, Taioli E. Meta- and pooled analyses of the effects of glutathione $S$ transferase M1 polymorphisms and smoking on lung cancer risk. Carcinogenesis 2002;23:13431350. [PubMed: 12151353]

21. Hung RJ, Boffetta P, Brockmoller J, Butkiewicz D, Cascorbi I, Clapper ML, Garte S, Haugen A, Hirvonen A, Anttila S, Kalina I, Le Marchand L, London SJ, Rannug A, Romkes M, Salagovic J, Schoket B, Gaspari L, Taioli E. CYP1A1 and GSTM1 genetic polymorphisms and lung cancer risk in Caucasian nonsmokers: a pooled analysis. Carcinogenesis 2003;24:875-882. [PubMed: 12771031] 
22. Vineis P, Veglia F, Benhamou S, Butkiewicz D, Cascorbi I, Clapper ML, Dolzan V, Haugen A, Hirvonen A, Ingelman-Sundberg M, Kihara M, Kiyohara C, Kremers P, Le Marchand L, Ohshima S, Pastorelli R, Rannug A, Romkes M, Schoket B, Shields P, Strange RC, Stucker I, Sugimura H, Garte S, Gaspari L, Taioli E. CYP1A1 T3801 C polymorphism and lung cancer: a pooled analysis of 2451 cases and 3358 controls. Int J Cancer 2003;104:650-657. [PubMed: 12594823]

23. Taioli E, Pedotti P. Pooled analysis on metabolic gene polymorphisms and lung cancer. Exp Lung Res 2005;31:217-222. [PubMed: 15824022]

24. Liu G, Zhou W, Christiani DC. Molecular epidemiology of non-small cell lung cancer. Semin Respir Crit Care Med 2005;26:265-272. [PubMed: 16052427]

25. LaVoie, EJ.; Rice, JE. Structure-activity relationships among tricyclic polynuclear aromatic hydrocarbons. In: Yang, SK.; Silverman, BD., editors. Polycyclic Aromatic Hydrocarbon Carcinogenesis: Structure-Activity Relationships. 1. CRC Press; Boca Raton, FL: 1988. p. 151-175.

26. International Agency for Research on Cancer. IARC Monographs on the Evaluation of the Carcinogenic Risk of Chemicals to Humans. 32. IARC; Lyon, FR: 1983. Polynuclear Aromatic Compounds, Part 1. Chemical, Environmental and Experimental Data; p. 419-430.

27. Simpson CD, Wu MT, Christiani DC, Santella RM, Carmella SG, Hecht SS. Determination of $r-7$, $t$-8, 9, $c$-10-tetrahydroxy-7, $8,9,10$ - tetrahydrobenzo[ $a]$ pyrene in human urine by gas chromatography-negative ion chemical ionization-mass spectrometry. Chem Res Toxicol 2000;13:271-280. [PubMed: 10775327]

28. Hecht SS, Carmella SG, Yoder A, Chen M, Li Z, Le C, Jensen J, Hatsukami DK. Comparison of polymorphisms in genes involved in polycyclic aromatic hydrocarbon metabolism with urinary phenanthrene metabolite ratios in smokers. Cancer Epidemiol Biomarkers \& Prev. 2006in press

29. Hecht SS, Chen M, Yoder A, Jensen J, Hatsukami D, Le C, Carmella SG. Longitudinal study of urinary phenanthrene metabolite ratios: effect of smoking on the diol epoxide pathway. Cancer Epidemiol Biomarkers \& Prev 2005;14:2969-2974.

30. Carmella SG, Chen M, Yagi H, Jerina DM, Hecht SS. Analysis of phenanthrols in human urine by gas chromatography-mass spectrometry: potential use in carcinogen metabolite phenotyping. Cancer Epidemiol Biomarkers \& Prev 2004;13:2167-2174.

31. Hecht SS, Chen M, Yagi H, Jerina DM, Carmella SG. $r$-1, $t$-2, 3, $c$-4- Tetrahydroxy-1, 2, 3, 4tetrahydrophenanthrene in human urine: a potential biomarker for assessing polycyclic aromatic hydrocarbon metabolic activation. Cancer Epidemiol Biomarkers \& Prev 2003;12:1501-1508.

32. Horning MG, Sheng LS, Nowlin JG, Lertratanangkoon K, Horning EC. Analytical methods for the study of urinary thioether metabolites in the rat and guinea pig. J Chromatogr 1987;399:303-319. [PubMed: 3654858]

33. Boyland E, Sims P. Metabolism of polycyclic compounds. 20. The metabolism of phenanthrene in rabbits and rats: mercapturic acids and related compounds. Biochem J 1962;84:564-570. [PubMed: 13872197]

34. DiRaddo P, Chan TH. Reactions of the K-Region Epoxides of Polycyclic Aromatic Hydrocarbons with Phosphodiesters. A Potential Detoxification Reaction. J Organ Chem 1982;47:1427-1431.

35. Boyland E, Sims P. Metabolism of polycyclic compounds. the metabolism of 9, 10-epoxy-9, 10dihydrophenanthrene in rats. Biochem J 1965;95:788-792. [PubMed: 14342516]

36. Cobb D, Boehlert C, Lewis D, Armstrong RN. Stereoselectivity of isozyme C of glutathione Stransferase toward arene and azaarene oxides. Biochemistry 1983;22:805-812. [PubMed: 6838824]

37. Robertson IGC, Guthenberg C, Mannervik B, Jernström B. Differences in stereoselectivity and catalytic efficiency of three human glutathione transferases in the conjugation of glutathione with $7 \beta, 8 \alpha$-dihyroxy-9 $\alpha, 10 \alpha$-oxy-7, 8, 9, 10- tetrahydrobenzo(a)pyrene. Cancer Res 1986;46:22202224. [PubMed: 3084065]

38. Jernström B, Seidel A, Funk M, Oesch F, Mannervik B. Glutathione conjugation of trans-3, 4dihydroxy 1, 2-epoxy 1, 2, 3, 4-tetrahydrobenzo[c]phenanthrene isomers by human glutathione transferases. Carcinogenesis 1992;13:1549-1555. [PubMed: 1394838]

39. Sundberg K, Widersten M, Seidel A, Mannervik B, Jernstrom B. Glutathione conjugation of bayand fjord-region diol epoxides of polycyclic aromatic hydrocarbons by glutathione transferase M1-1 and P1-1. Chem Res Toxicol 1997;10:1221-1227. [PubMed: 9403173] 
40. Sundberg K, Dreij K, Seidel A, Jernstrom B. Glutathione conjugation and DNA adduct formation of dibenzo[a, 1]pyrene and benzo[a]pyrene diol epoxides in V79 cells stably expressing different human glutathione transferases. Chem Res Toxicol 2002;15:170-179. [PubMed: 11849043]

41. Warholm M, Guthenberg C, Mannervik B, von Bahr C. Purification of a new glutathione $S$-transferase (transferase $\mu$ ) from human liver having high activity with benzo $(\alpha)$ pyrene-4, 5-oxide. Biochem Biophys Res Commun 1981;98:512-519. [PubMed: 7194639]

42. Eaton DL, Bammler TK. Concise review of the glutathione S-transferases and their significance to toxicology. Toxicol Sci 1999;49:156-164. [PubMed: 10416260]

43. Sundberg K, Johansson AS, Stenberg G, Widersten M, Seidel A, Mannervik B, Jernstrom B. Differences in the catalytic efficiencies of allelic variants of glutathione transferase P1-1 towards carcinogenic diol epoxides of polycyclic aromatic hydrocarbons. Carcinogenesis 1998;19:433-436. [PubMed: 9525277]

44. Haufroid V, Lison D. Mercapturic acids revisited as biomarkers of exposure to reactive chemicals in occupational toxicology: a minireview. Int Arch Occup Environ Health 2005;78:343-354. [PubMed: 15883816] 

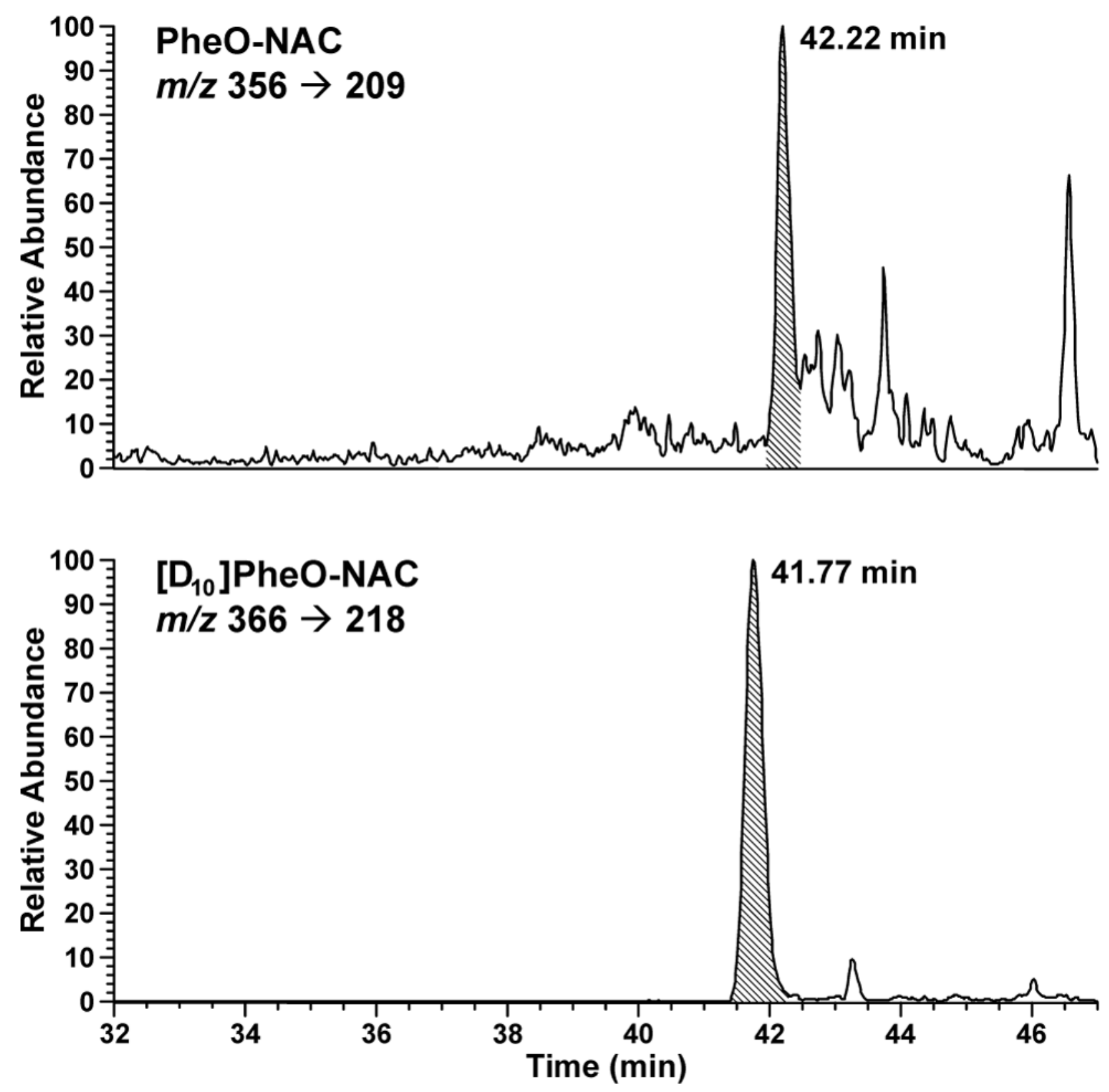

Figure 1.

Chromatogram obtained upon LC-ESI-MS/MS-SRM analysis of PheO-NAC in human urine ( $\mathrm{HCOOH} / \mathrm{CH}_{3} \mathrm{CN}$ elution system, see Materials and Methods). Upper panel, SRM for $\mathrm{m} / z 356$ $\rightarrow 209$ (PheO-NAC); lower panel, $m / z 366 \rightarrow 218$ ([D $\left.{ }_{10}\right]$ PheO-NAC, internal standard) 

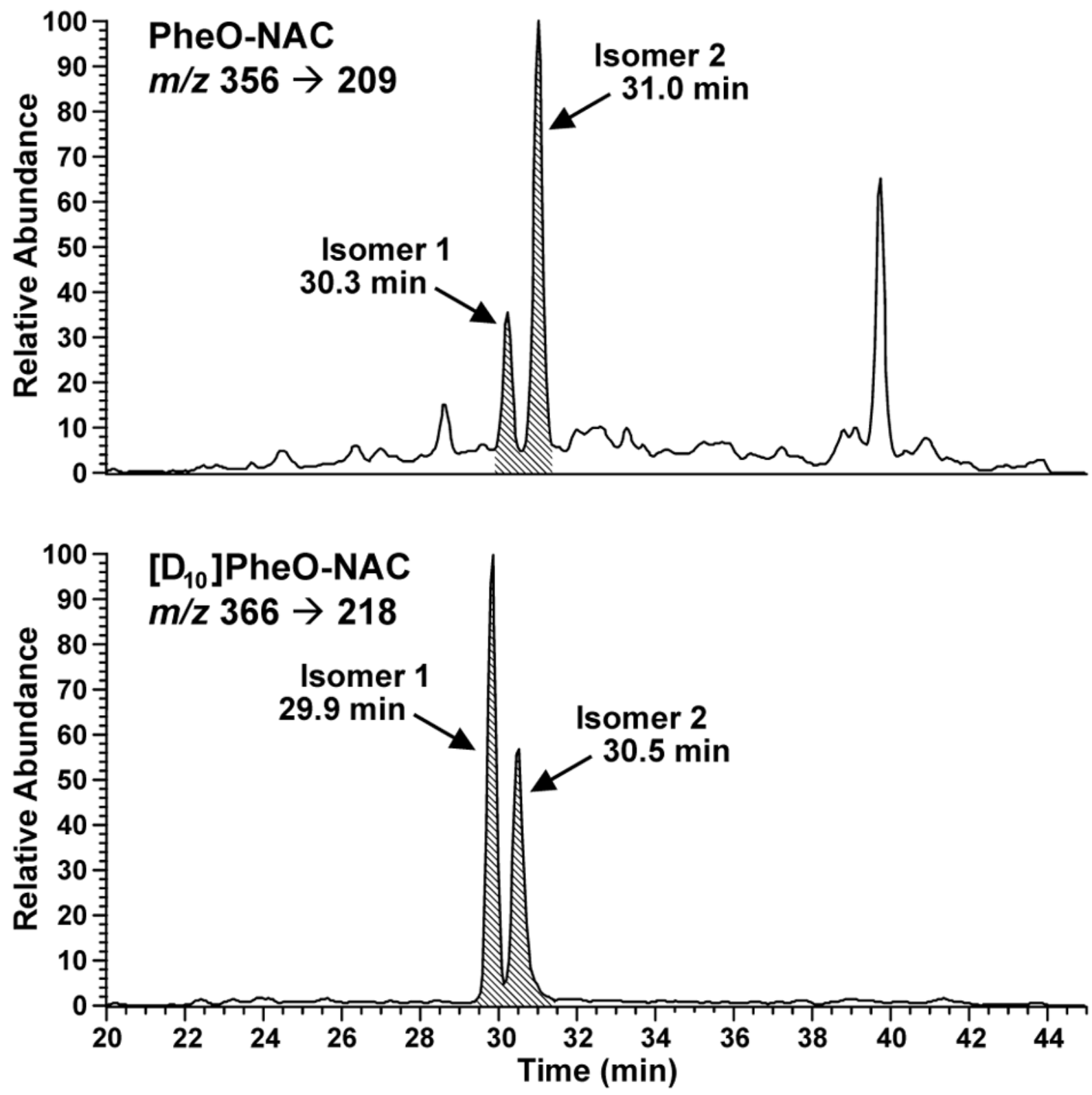

Figure 2.

Chromatogram obtained upon LC-ESI-MS/MS-SRM analysis of PheO-NAC in human urine $\left(\mathrm{NH}_{4} \mathrm{OAc} / \mathrm{CH}_{3} \mathrm{OH}\right.$ elution system, see Materials and Methods). Upper panel, SRM for $\mathrm{m} / z 356$ $\rightarrow 209$ (PheO-NAC); lower panel, $m / z 366 \rightarrow 218$ ([D 10$]$ PheO-NAC, internal standard) 

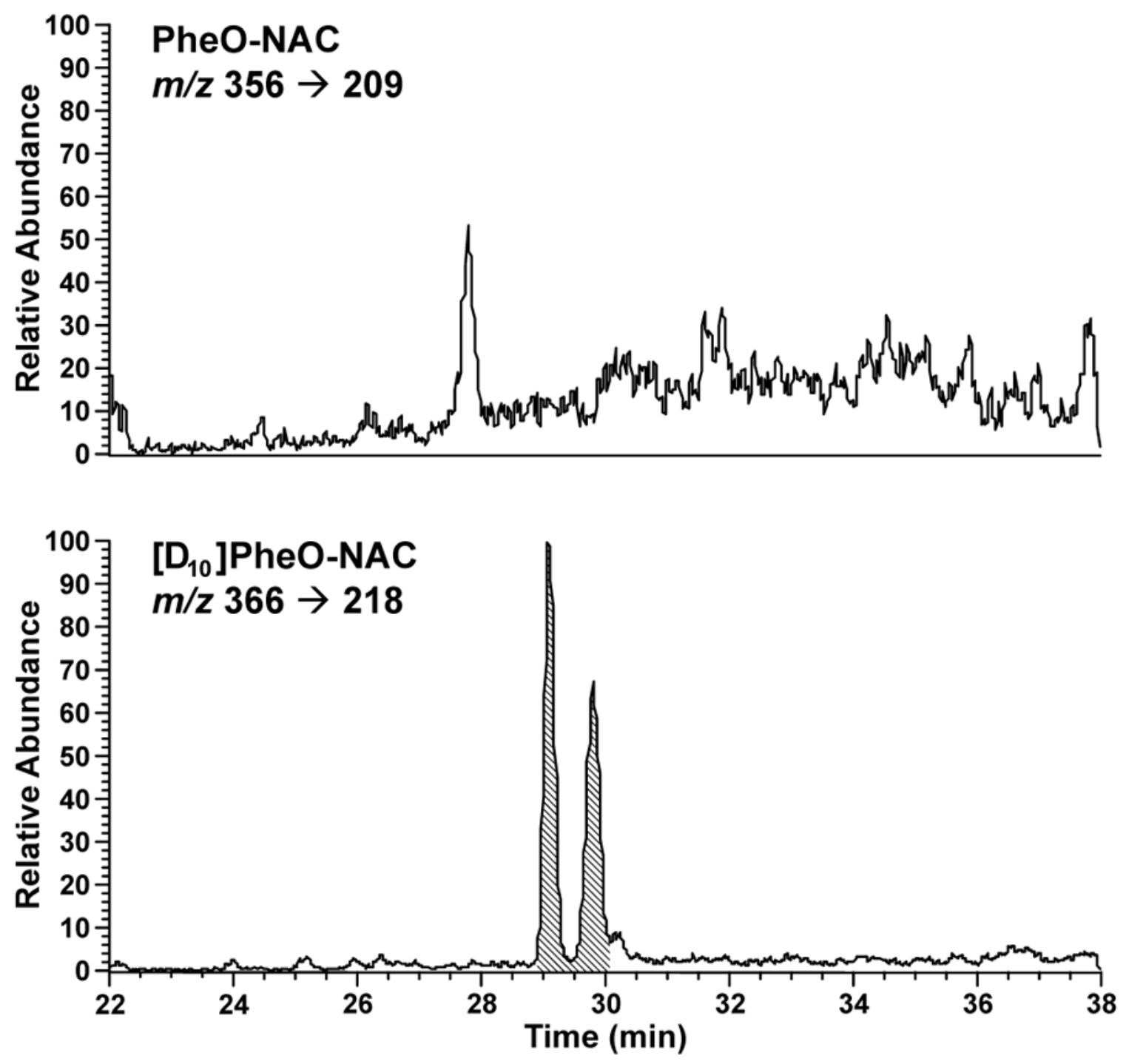

Figure 3.

Chromatogram obtained LC-ESI-MS/MS-SRM analysis of a urine sample negative for PheONAC $\left(\mathrm{NH}_{4} \mathrm{OAc} / \mathrm{CH}_{3} \mathrm{OH}\right.$ elution system, see Materials and Methods). Upper panel, SRM for $m / z 356 \rightarrow 209$ (PheO-NAC); lower panel, $m / z 366 \rightarrow 218$ ([D 10$]$ PheO-NAC, internal standard) 


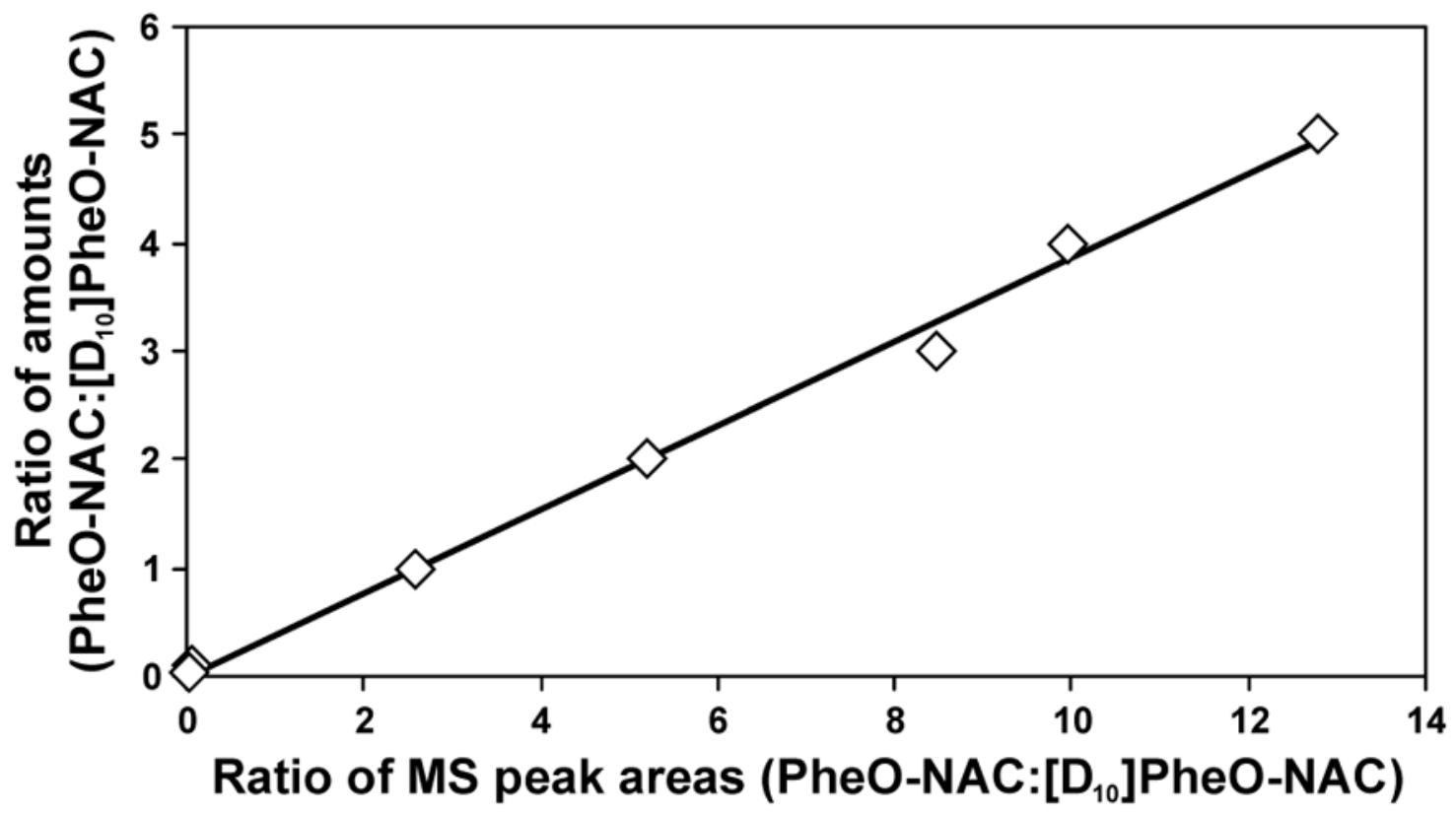

Figure 4.

Calibration curve relating ratio of PheO-NAC: $\left[\mathrm{D}_{10}\right] \mathrm{PheO}-\mathrm{NAC}$ to LC-ESI-MS/MS peak areas, $\mathrm{R}^{2}=0.99$. The calibration curve was constructed using $50-5000 \mathrm{fmol}$ PheO-NAC and 1000 fmol $\left[\mathrm{D}_{10}\right]$ PheO-NAC 


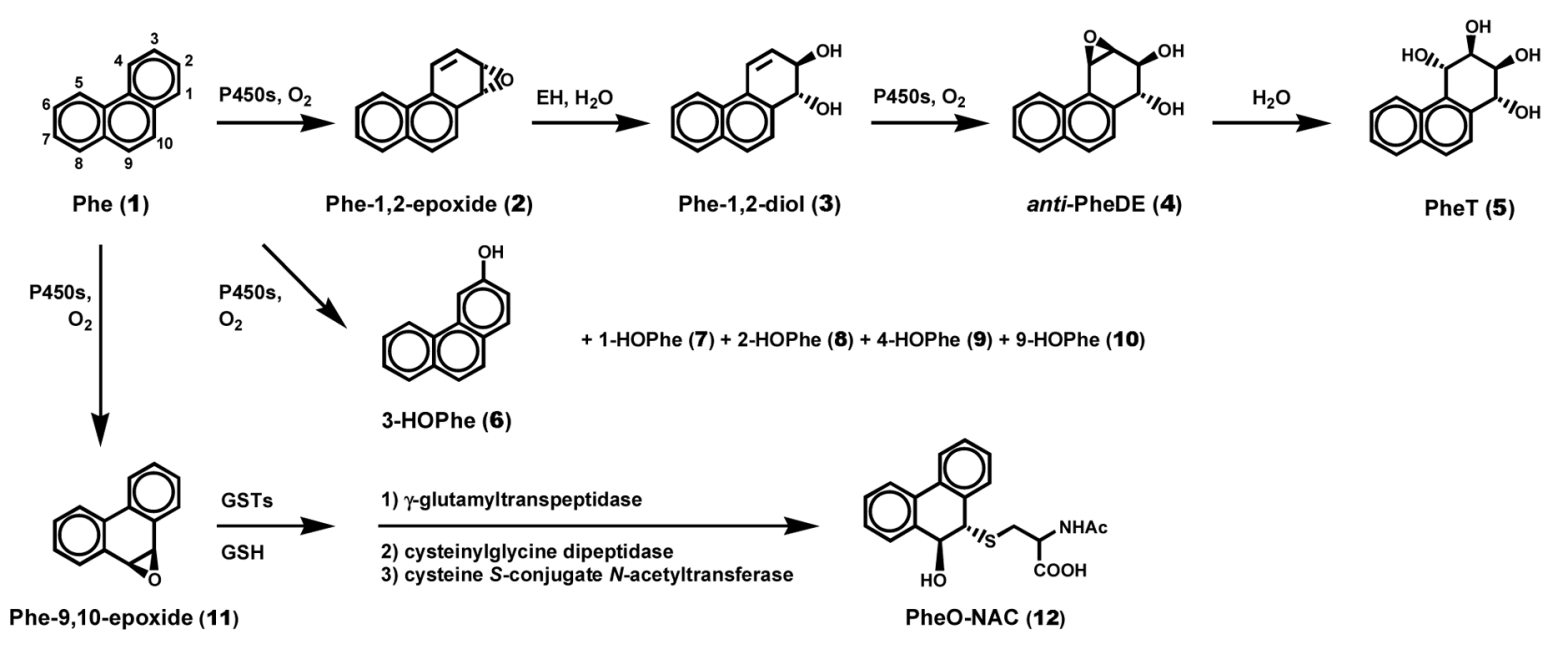

Scheme 1.

Overview of Phenanthrene (Phe) Metabolism 


\section{Urine (5 mL) \\ $+$ \\ $\left[\mathrm{D}_{10}\right]$ PheO-NAC}

\section{Solid Phase Extraction}

1) Oasis MCX reverse phase enrichment

2) Oasis MAX anion exchange enrichment

3) Strata $X$ - desalting

\section{LC-ESI-MS/MS-SRM \\ $m / z 356 \rightarrow 209$ (PheO-NAC) \\ $m / z 366 \rightarrow 218\left(\left[D_{10}\right]\right.$ PheO-NAC)}

Scheme 2.

Analytical Method for Quantitation of PheO-NAC in Human Urine 
Table 1

Levels of PheO-NAC (12) in smokers' urine (positive samples only)

\begin{tabular}{rrrr}
\hline Smoker & PheO-NAC (fmol/ml) & Smoker & PheO-NAC (fmol/ml) \\
& & 24 & 30 \\
1 & 560 & 25 & 100 \\
2 & 99 & 26 & 310 \\
3 & 20 & 27 & 23 \\
4 & 42 & 28 & 21 \\
5 & 71 & 29 & 25 \\
6 & 100 & 30 & 92 \\
7 & 42 & 31 & 51 \\
8 & 48 & 32 & 31 \\
9 & 30 & 33 & 55 \\
10 & 190 & 34 & 26 \\
11 & 41 & 35 & 140 \\
12 & 55 & 36 & 95 \\
13 & 70 & 37 & 40 \\
14 & 570 & 39 & 68 \\
15 & 880 & 40 & 82 \\
16 & 530 & 41 & 52 \\
18 & 680 & 42 & 35 \\
19 & 150 & 43 & 33 \\
20 & 7 & 44 & 98 \\
21 & 70 & 45 & 210 \\
23 & 47 & 46 & \\
\hline
\end{tabular}

